'Molecular characterization of a gilthead sea bream (Sparus aurata) muscle tissue cDNA for carnitine palmitoyltransferase 1B (CPT1B)' by Evridiki

Boukouvala, Michael J. Leaver, Laurence Favre-Krey, Maria Theodoridou, and Grigorios Krey. Comparative Biochemistry and Physiology Part B: Biochemistry and Molecular Biology, Volume 157, Issue 2, October 2010, pp. 189 - 197.

Published in Comparative Biochemistry and Physiology Part B: Biochemistry and Molecular Biology by Elsevier. Comparative Biochemistry and Physiology Part B: Biochemistry and Molecular Biology, Volume 157, Issue 2, October 2010, pp. 189 - 197.

This is the peer reviewed version of this article.

NOTICE: this is the author's version of a work that was accepted for publication in Comparative Biochemistry and Physiology Part B: Biochemistry and Molecular Biology. Changes resulting from the publishing process, such as peer review, editing, corrections, structural formatting, and other quality control mechanisms may not be reflected in this document. Changes may have been made to this work since it was submitted for publication. A definitive version was subsequently published in Comparative Biochemistry and Physiology Part B: Biochemistry and Molecular Biology, VOL 157, ISSUE 2, (October 2010). DOI 10.1016/j.cbpb.2010.06.004. 


\title{
Molecular characterization of a gilthead sea bream (Sparus aurata) muscle tissue cDNA for carnitine palmitoyltransferase 1B (CPT1B).
}

\author{
Evridiki Boukouvala ${ }^{\mathrm{a}}$, Michael J. Leaver ${ }^{\mathrm{b}}$, Laurence Favre-Krey ${ }^{\mathrm{a}}$, Maria Theodoridou, \\ Grigorios Krey, ${ }^{\mathrm{a}, 2}$
}

${ }^{a}$ National Agricultural Research Foundation, Fisheries Research Institute, Nea Peramos, GR64007 Kavala, Greece.

${ }^{\mathrm{b}}$ Institute of Aquaculture, University of Stirling, Stirling FK9 4LA, United Kingdom

${ }^{2}$ Corresponding author: National Agricultural Research Foundation, Fisheries Research

Institute, Nea Peramos, GR-64007 Kavala, Greece, Fax: +30-25940 22222,

e-mail: krey@otenet.gr

\begin{abstract}
Understanding the control of piscine fatty acid metabolism is important for determining the nutritional requirements of fish, and hence for the production of optimal aquaculture diets. The regulation and expression of carnitine palmitoyltransferase 1 (CPT1; EC No 2.3.1.21) are critical processes in the control fatty acid metabolism, and here we report a cDNA from gilthead sea bream (Sparus aurata) which encodes a protein with high identity to vertebrate CPT1. This sea bream CPT1 mRNA is predominantly expressed in skeletal and cardiac muscle, with little expression in other tissues. Phylogenetic analysis of other vertebrate CPT1 sequences show that fish genomes contain a single gene related to mammalian CPT1B, and a further two multi-gene families related to mammalian CPT1A. Genes related to mammalian CPT1C are absent in fish. Therefore, based on both functional and evolutionary orthology to mammalian CPT1B, the sea bream CPT1 reported here is a CPT1B isoform. Sea bream CPT1B mRNA expression progressively decreases in heart and muscle up to 12 hours after last feeding, but returns to initial, non-fasted levels after 72 hours. In contrast, in liver non-fasted expression is low, but strongly increases at 24 and 72 hours after last feeding. In white muscle and liver, CPT1B mRNA expression is highly correlated with the expression of peroxisomal proliferator-activated receptor $\square$ (PPAR $\square$ ). Thus fatty acid metabolism by CPT1B and its control by PPARs is similar in fish and mammals, but multiple genes for CPT1A-like proteins in fish also suggest different and more complex pathways of lipid utilisation than in mammals.
\end{abstract}

\section{INTRODUCTION}

Carnitine palmitoyltransferase 1 (CPT1, EC2.3.1.21) along with carnitine palmitoyltransferase 2 (CPT2) forms the mitochondrial carnitine palmitolyltransferase system, which mediates the uptake of long-chain fatty acids to the mitochondrion (McGarry and Brown, 1997). CPT1 is anchored in the outer mitochondrial membrane and catalyzes the transfer of fatty acyl groups from coenzyme A to carnitine. Acylcarnitine transverses the inner mitochondrial membrane by means of a specific translocase and fatty acyl-CoAs within the matrix are regenerated by CPT2. CPT1, by virtue of its inhibition by malonyl-CoA is the main regulatory point in fatty acid $\beta$ oxidation with increasing levels of malonyl-CoA favouring fatty acid utilisation in biosynthesis This process is central in maintaining an effective fuel "cross talk", which according to the energy needs of the organism can lead to either catabolism or biosynthesis of fatty acids in a variety of tissues such as the liver, heart, and the skeletal muscle (Britton et al., 1995). Consequently, the study of CPT1 in mammals has gathered considerable interest as one potential target for the pharmacological 
control of fatty acid oxidation.

In mammals, CPT1 is encoded by three genes, one being expressed predominantly in the liver (CPT1A) and the second (CPT1B) in the skeletal muscle (Esser et al., 1996). The muscle and liver isoforms are $62 \%$ identical in amino acid sequence and exhibit different sensitivity to malonyl-CoA inhibition (Treber et al., 2003). A third more distantly related isoform of the enzyme (CPT1C) which is restricted to the central nervous system and functions in the control of whole-body glucose homeostasis has been recently described in mammalian species (Price et al., 2002, Gao et al., 2009).

Further to differences in regulation at the catalytic level, the mammalian CPT1 isoforms are also differentially regulated at the gene level. Thus, CPT1A is primarily hormonally regulated, while CPT1B is primarily fuel-regulated (Cook et al., 2001). It is currently well established that fatty acids, peroxisome proliferators, as well as physiological conditions such as feeding and fasting affect the expression of the CPT1 genes (Yu et al., 1998, Brandt et al., 1998). Key mediators of these processes are the peroxisome proliferator-activated receptors, PPAR (Baldán et al., 2004, Gilde et al., 2003, Mescaró et al., 1998), which have been described as transcription factors at the crossroads of diet and hormonal signalling (Desvergne et al., 1998).

The regulation of fatty acid and lipid metabolism at the gene level has been poorly studied in fish species, despite the fact that problems related to fatty acid metabolism are of primary importance to modern aquaculture practices (Leaver et al., 2008). Molecular studies concerning CPT1 expression in fish are presently limited to rainbow trout (Oncorhynchus mykiss), i.e. the species in which a CPT1 encoding sequence was first identified (Gutières et al., 2003). Although it was originally proposed that trout expressed a single CPT1 gene corresponding to the mammalian liver isoform (Gutières et al., 2003), further studies of CPT1 sensitivity for malonyl-CoA, coupled to determination of relative mRNA expression levels, in the tissues of thefish suggested the presence of additional isoform(s) (Morash et al.,2008). Indeed, another three CPT1-like sequences have recently been identified in trout, and their expression has subsequently been studied in response to nutritional and hormonal stimuli, and in relation to the expression of other genes encoding enzymes involved in fatty acid metabolism, including two trout PPAR isotypes (Kolditz et al., 2008; Lansard et al., 2009; Morash et al., 2009; Plagnes-Juan et al., 2008; Polakof et al., 2010). However, these four trout isoforms have been arbitrarily termed CPT1a-d (Kolditz et al., 2008), a nomenclature not based on functional/evolutionary orthology to the mammalian CPT1isoforms. Therefore, a more systematic study of the evolutionary relationship of the piscine CPT1 isoforms to their mammalian counterpartsis needed. This, in turn, will aid the further understanding of CPT1function in fish, specifically regarding the identification of factors that are involved in its regulation, at both the gene and enzyme levels.

Herein, we describe the identification and molecular characterization of a cDNA from the muscle tissue of an important aquaculture species, gilthead sea bream (Sparus aurata, sea bream hereafter), that encodes a protein with high similarity to CPT1 proteins from other species. By employing phylogenetic and tissue mRNA expression analyses we show that the deduced sea bream protein is likely to be the muscle CPT1 isoform (CPT1B). In addition, by utilising available fish genome data, we aimed to elucidate the evolutionary relationships amongst fish and the better chracterised mammalian CPT1 isoforms. Accordingly, we show that fish species contain a single CPT1B-like gene and multiple genes for CPT1A-like proteins. Furthermore, we test the hypothesis that the expression of sea bream CPT1B is regulated at the mRNA level depending on the prandial state of the fish, and is related to PPAR mRNA levels. 


\section{MATERIAL AND METHODS}

\subsection{Animals}

Sea bream (S. aurata, Sparidae, Percomorpha,) were obtained from farmed stock (Interfish, Larimna, Greece). The fish were maintained in recirculating sea water in the indoor facility of the Fisheries Research Institute under natural photoperiod and constant water temperature $\left(19-20{ }^{\circ} \mathrm{C}\right)$ conditions for approximately eight months. Prior to use, fish were fed a commercial diet (Excel $1^{\circ}$, Skretting) containing 20\% fat, $48 \%$ protein. Sea bream is a protandrous species undergoing sex reversal after the second year of their lives. The fish used in this study aged 10 months and therefore were all male. Before sampling, fish were anaesthetized and killed by decapitation. Unless otherwise noted, fish were sampled at $24 \mathrm{~h}$ following last feeding.

\subsection{RNA isolation and synthesis of cDNA}

Total RNA from sea bream tissues, i.e. brain, liver, intestinal (proximal to cecum), gills, heart, red muscle, white muscle, and mesenteral adipose tissue, was extracted with the RNeasy tissue kit (Qiagen) according to the manufacturers instructions. One microgram of total red muscle RNA was used for reverse transcription with the Expand Reverse Transcriptase (Roche Applied Science) and an oligo-dT primer. Two microlitres of the cDNA thus obtained were used as template for PCR with the forward primer CPT5' $\mathrm{F}$ and the reverse primer CPT5'R1 $(0.25 \mu \mathrm{M}$, final concentration). Both of these primers were designed according to a rainbow trout CPT1 cDNA sequence (GenBank access. no. AF327058). In addition to the above, PCR conditions included 1.5 units of Pfusion DNA polymerase (Finnzymes) and dNTPs $(0.2 \mu \mathrm{M}$, final concentration) in a final volume of $50 \mu$ l. The cycler program and primer sequences are given in Table 1. The resulting $1350 \mathrm{bp}$ fragment, which encoded the 450 amino-terminal residues including the initiation methionine of the sea bream CPT1, was ligated into the PCR4TOPO vector (Invitrogen) and was propagated as a plasmid insert for further analyses.

\subsection{Rapid amplification of the 3' cDNA end (3'-RACE)}

The sequences encoding the carboxy-terminus of CPT1 were obtained through 3'-rapid amplification of cDNA ends PCR (3'-RACE) using a commercial kit (5', 3' RACE kit, Roche Applied Science) on cDNA synthesized with the oligo-dT anchor primer provided by the kit and the gene-specific primer CPTF3'3. The primer sequences and thermocycling program are given in Table 1 . The resulting 1124 bp amplification product, encoding the 363 carboxyterminal residues of the protein, was inserted into the pCR-Script Amp SK(+) vector (Stratagene) for further analyses.

\subsection{Deduced protein sequence and phylogenetic analyses}

Hydrophobicity regions and/or potential transmembrane helices within the deduced protein sequence of the sea bream CPT1 were calculated with the algorithms available in the OMIGA 2.0 software package (Accelerys). Functional motifs were identified by a PROSITE search (http://au.expasy.org/prosite). For phylogenetic tree construction, the amino acid sequences of the sea bream protein along with the CPT1 isoforms from other species were aligned using the OMIGA 2.0 software package. Amino acid sequences for pufferfish (Tetraodon nigroviridus) and zebrafish CPT1 proteins were obtained from gene sequences predicted from Ensembl/Genbank genome databases. The alignment file was used to construct neighboring-joining trees using the MEGA 2 (Kumar et al., 2001) and/or the PAUP 4b 
(Swofford, 2000) software packages. The trees were tested for robustness by "bootstrapping" through 1000 iterations.

Table 1. Primer sequences and PCR conditions for cloning and expression analysis

\begin{tabular}{|c|c|c|c|c|}
\hline $\begin{array}{l}\text { Primer } \\
\text { Pairs }\end{array}$ & Gene & Sequence & Application & $\begin{array}{c}\text { Amplification } \\
\text { Conditions }\end{array}$ \\
\hline $\begin{array}{l}\text { CPT5'F } \\
\text { CPT5'R1 }\end{array}$ & CPT1 & $\begin{array}{l}\text { 5'-GATGGCAGAGGCACATCAGG } \\
\text { 5'-TGGAGCACATAGGAACGGTCC }\end{array}$ & RT-PCR ${ }^{\text {a) }}$ & $\begin{array}{l}94^{\circ} \mathrm{C}-4 \mathrm{~min}\left[\left(94^{\circ} \mathrm{C}-30\right.\right. \\
\mathrm{sec} / 56^{\circ} \mathrm{C}-30 \mathrm{sec} / 72^{\circ} \mathrm{C}- \\
1 \mathrm{~min}) 10 \mathrm{cycles}+ \\
\left(94^{\circ} \mathrm{C}-30 \mathrm{sec} / 55^{\circ} \mathrm{C}-30\right. \\
\mathrm{sec} / 72^{\circ} \mathrm{C}-1 \mathrm{~min}+5 \mathrm{sec} \\
/ \mathrm{cycle}) 25 \mathrm{cycles}] / \\
72^{\circ} \mathrm{C}-7 \mathrm{~min}\end{array}$ \\
\hline $\begin{array}{l}\text { CPTF3'3 } \\
\text { Anchor }^{\text {b) }}\end{array}$ & CPT1 & $\begin{array}{l}\text { 5'-TGCCATTGAGTCAGCTGCCTTCTTC } \\
\text { 5'- GACCACGCGTATCGATGTCGAC }\end{array}$ & 3'-RACE & $\begin{array}{l}94^{\circ} \mathrm{C}-4 \min \left(94^{\circ} \mathrm{C}-30 \mathrm{sec}\right. \\
/ 56^{\circ} \mathrm{C}-30 \mathrm{sec} / 72^{\circ} \mathrm{C}-90 \\
\text { sec) } 35 \text { cycles } / 72^{\circ} \mathrm{C}-7 \\
\min \end{array}$ \\
\hline $\begin{array}{l}\text { QSaCPT1BF } \\
\text { QSaCPT1BR }\end{array}$ & CPT1 & $\begin{array}{l}\text { 5'-CAAGCCCCGACACAGACTCATACC } \\
\text { 5'-CCCATTTCCCAGCTGCGTTATTTT }\end{array}$ & $\mathrm{Q}^{-} \mathrm{PCR}^{\mathrm{c})}$ & $\begin{array}{l}95^{\circ} \mathrm{C}-10 \mathrm{~min}\left(95^{\circ} \mathrm{C}-30\right. \\
\left.\mathrm{sec} / 60^{\circ} \mathrm{C}-1 \mathrm{~min}\right) 45 \\
\text { cycles }{ }^{d)}\end{array}$ \\
\hline $\begin{array}{l}\text { QSaPPARaF } \\
\text { QSaPPARaR }\end{array}$ & $\operatorname{PPAR} \alpha$ & $\begin{array}{l}\text { 5'- } \\
\text { CTGAATGATCAGGTGACTCTCTTGAAG } \\
\text { 5'- } \\
\text { CCTGGGCGATCTCCGCAGCAGATAATG }\end{array}$ & Q-PCR & Idem \\
\hline $\begin{array}{l}\text { QSaPPARbF } \\
\text { QSaPPARbR }\end{array}$ & PPAR $\beta$ & $\begin{array}{l}\text { 5'-TGCGGTCAAGTTCAATGCTCT } \\
\text { 5'-GACTCTGCTCCACCTGCTTCA }\end{array}$ & Q-PCR & Idem \\
\hline $\begin{array}{l}\text { QSaPPARgF } \\
\text { QSaPPARgR }\end{array}$ & $\operatorname{PPAR} \gamma$ & $\begin{array}{l}\text { 5'-ATGATGGCACCTCTGATGAACAA } \\
\text { 5'-TGAGATAATGACAGCCAGAAACA }\end{array}$ & Q-PCR & Idem \\
\hline $\begin{array}{l}\text { QSaEF1aF } \\
\text { QSaEF1aR }\end{array}$ & EF1a & $\begin{array}{l}\text { 5'-CATGGTTGTGGAGCCCTTCT } \\
\text { 5'-TCCTGCACGACCATTCATTTC }\end{array}$ & Q-PCR & Idem \\
\hline
\end{tabular}

\footnotetext{
a) Reverse transcription followed by PCR

b) 5'/3' RACE kit (Roche Applied Science) Anchor primer

${ }^{c)}$ Quantitative real-time PCR

${ }^{\text {d) }}$ Followed by generation of a melt curve by measuring fluorescence during heating from $55^{\circ} \mathrm{C}$ to $95^{\circ} \mathrm{C}$
}

\subsection{Riboprobes and RNase protection assay}

The presence of CPT1B transcripts in different sea bream tissues was examined by the RNase protection assay using a commercial kit (RNase protection kit, Roche Applied Science). For the CPT1 riboprobe, the 5'-end fragment of the CPT1 cDNA in the PCR4-TOPO vector (see above) was digested with the Bam $\mathrm{HI}$ and Eco RI restriction endonucleases and the resulting $260 \mathrm{bp}$ fragment (positions 1091-1350 of the cDNA) was inserted into the corresponding sites of pBluescript II KS (Stratagene). The recombinant plasmid was digested with Not I and the antisense riboprobe was synthesized by $\mathrm{T} 3$ polymerase transcription (Promega). The synthesis of the sea bream $\beta$-actin riboprobe has been previously described 
(Leaver et al., 2005). Riboprobes were labeled with $\left[\alpha-{ }^{32} \mathrm{P}\right] \mathrm{CTP}(800 \mathrm{Ci} / \mathrm{mmol}$, Amersham Biosciences Europe) and the RNase protection assay was performed as previously described (Boukouvala et al., 2004, Leaver et al., 2005) on $8 \mu \mathrm{g}$ of total RNA from each tissue sample. The protected fragments were separated on a $6 \%$ polyacrylamide gel containing $7 \mathrm{M}$ urea. Signals were visualized by autoradiography.

\subsection{Quantitative real-time PCR (Q-PCR)}

Extraction of total RNA from fish tissues and first strand cDNA synthesis were performed as described above. The cDNA synthesis reactions were diluted to $200 \mu \mathrm{l}$ in water. QPCR reactions $(20 \mu \mathrm{l})$ contained $10 \mu \mathrm{l}$ of the Briliant II SYBR Green QPCR Master Mix (Stratagene), $2 \mu 1$ of cDNA, and $75 \mathrm{nM}$ of each primer. No-template control reactions were included for each target gene. PCR was performed in 96-well plates in a Stratagene (Agilent) Mx3000P thermocycler. The $133 \mathrm{bp}$ fragment of CPT1B cDNA (positions 2208-2348 of cDNA, GenBank DQ866821) was amplified with primers QSaCPT1BF and QSaCPT1BR; the $265 \mathrm{bp}$ fragment of sea bream PPAR $\alpha$ cDNA (positions 1028-1293 of cDNA, GenBank AY590299) was amplified with primers QSaPPARaF and QSaPPARaR; the 119 bp fragment of sea bream PPAR $\beta$ cDNA (positions 1393-1511 of cDNA, GenBank AY590301) was amplified with primers QSaPPARbF and QSaPPARbR; the $195 \mathrm{bp}$ fragment of sea bream PPAR $\gamma$ cDNA (positions 1387-1582 of cDNA, GenBank AY590304) was amplified using primers QSaPPARgF and QSaPPARgR. The relative expression of PPAR and CPT1B genes was calculated with the "delta-delta Ct" method (Pfaffl, 2001), where elongation factor 1a (EF1a) was used as a reference gene. The 166 bp fragment of sea bream EF1a cDNA (positions 12341407 of cDNA, GenBank AF184170) was amplified with primers QSaEF1aF and QSaEF1aR. The thermocycling program and primer sequences used in this analysis are given in Table 1. All reactions were performed in duplicates and each reaction was verified to contain a single product of the correct size by agarose gel electrophoresis. Amplification of the correct targets was further confirmed by DNA sequencing. Statistical differences between samples were determined by one-way ANOVA, followed by the Tukey post test, using the STATISTICA 7 (StatSoft) software package.

\subsection{Post-prandial experiments}

Fish aged 10 months and of average weight $200 \pm 50 \mathrm{~g}$ were kept unfed for a $24 \mathrm{~h}$ period, at the end of which they were allowed to feed to satiation. One hour after feeding five fish were removed and tissues (heart, red muscle, white muscle, and liver) were excised for RNA extraction, as described above. The same procedure was followed for fish that were removed from the tank at $3,5,8,12,24$, and $72 \mathrm{~h}$ after feeding. The progression of food through the digestive tract (stomach, intestine, and rectum) was recorded at each sampling time point and was used to select fish for the mRNA expression analysis. Under the conditions of this experiment, food evacuation started as early as $3 \mathrm{~h}$ post-feeding (presence of digested material in the rectum) and it was completed between the 24 and $72 \mathrm{~h}$ time points (digestive tract was completely empty).

\section{RESULTS}

\subsection{Cloning of the CPT1 cDNA and analysis of the deduced protein sequence.}

The previous identification of a partial cDNA encoding the amino-terminus of a CPT1 protein from rainbow trout (Gutières et al., 2003) demonstrated a high degree of sequence conservation between mammalian and teleost CPT1 at both the nucleotide and amino acid 
levels. Thus, oligonucleotide primers were designed with sequences corresponding to regions of high identity between the reported trout and mammalian cDNA sequences. At the time that this work was initiated the complete coding sequence of the trout CPT1 was not known. Therefore, we initially performed reverse transcription coupled to PCR (RT-PCR) on total RNA isolated from sea bream red muscle with a forward primer encompassing the presumed initiation codon along with a reverse primer corresponding to nucleotides 1546-1566 of the trout cDNA. Through this approach, a $1350 \mathrm{bp}$ amplicon was obtained, which upon sequence analysis was found to encode the 450 amino-terminal residues of the sea bream CPT1. To identify the sequences encoding the carboxy-terminus of the protein, a gene-specific primer was designed (nt positions 1224-1248 of the sea bream cDNA) and was used in 3'-RACE PCR. This approach resulted in the amplification of an $1124 \mathrm{bp}$ fragment that included the sequences encoding the 367 carboxy-terminal residues of the protein, as well as $16 \mathrm{bp}$ of 3'-untranslated sequence.

The complete deduced amino acid sequence of the sea bream CPT1 is shown in Fig. 1. The protein contains 776 residues and exhibits extended sequence homology with CPT1 proteins from other species. Within this protein, hydrophobicity analysis predicts the presence of two transmembrane helices spanning residues 50-80 and 100-136. Further, a functional motifs search predicts the presence of two carnitine acyltransferase sites within residues 171186 and 449-476, two potential asparagine glycosylation sites at residues 312 and 367, as well as a potential tyrosine phosphorylation site at residue 191. Most of these residues are conserved in the proteins from other species (Fig. 1).

\subsection{Phylogenetic analysis of the sea bream CPT1.}

In mammals, the liver and the heart/skeletal muscle CPT1 isoforms share $62 \%$ identical residues. The alignment of Fig. 1 shows that the sea bream CPT1 shares almost equal levels of identity with the human liver and muscle isoforms, 67 and 66\%, respectively, while it shares $80 \%$ identical residues with the previously reported trout protein (Gutières et al., 2003). Although this information provides strong evidence that the sea bream protein is homologous to that of trout, it does not allow conclusions on whether, in either species, it represents the liver or the muscle isoform. We addressed this question by constructing phylogenetic trees where the sea bream protein sequence was compared with CPT1 sequences from a variety of species. Attempts were made to include only apparent full length polypeptides in these comparisons and, thus, sequences were derived initially from BLAST searches of GenBank against sea bream CPT1, followed by prediction of full length sequences from Danio rerio (zebrafish) and Takifugu rubripes (pufferfish) genomic data. The consensus neighbouring-joining tree depicted in Fig. 2 demonstrates that the sea bream sequence, along with the originally reported trout sequence (GenBank:AF327058, Gutières et al., 2003), clusters robustly with the mammalian CPT1B sequences. Similarly, the robust bootstrap value at the node of the CPT cluster containing human CPT1A, which includes two zebrafish sequences (GenBank:AL929208 and XM_683391), one trout sequence (GenBank:AJ691768), and a pufferfish polypeptide derived from genomic sequence, along with the Xenopus and chick sequences, show that fish also possess representatives of the CPT1A family, distinct from CPT1B. This tree also demonstrates that the mammalian CPT1C isoform is distantly related to either the A or B isoforms and forms a distinct clade. No fish sequences were positioned within the CPT1C clade. It is also clear from this phylogeny that fish possess a further CPT1 family, shown by the distinct clustering of two genes predicted from each of the zebrafish and pufferfish genomes and a trout cDNA (GenBank:AJ620356). There are no mammalian genes in this family and its position in the phylogenetic tree indicates that it may be a subfamily of CPT1A. 
Sa CPT I MAEAHQAVGFQFTVRPDGVDLKLSQEVIKNIYLSGVTAWKKRAIQFKNGVLAGVYPASPS

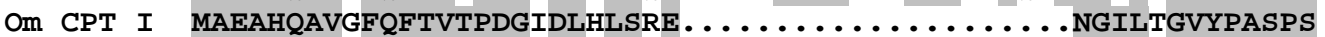
Hs CPT IA MAEAHQAVAFQFTVTPDGIDLRLSHEALRQIYLSGLHSWKKKF IRFKNGIITGVYPASPS Hs CPT IB MAEAHQAVAFQFTVTPDGVDFRLSREALKHVYLSGINSWKKRLIRIKNGILRGVYPGSPT

Sa CPT I SWLIVVIAMMSSLYIRVDPSLGMIDAIKENLPHRDYLSA. QTRAVLSAILFATGLWLFL Om CPT I SLLIVVITIMSTIYARIDPSLGMIDTIKRTMSVSGYMTV. .QTQTVLSAILFSTGLWLSL HS CPT IA SWLIVVVGVMTTMYAKIDPSLGIIAKINRTLETANCMSS. .QTKNVVSGVLFGTGLWVAL Hs CPT IB SWLVVIMATVGSSFCNVDISLGLVSCIQRCLPQGCGPYQTPQTRALLSMAIFSTGVWVTG

Sa CPT I IYLLRYTLKALLSYHGWIFESHGKMSTSTKLWLSLVKMFSGRRPLLYSFQASLPRLPVPS Om CPT I ILMLRYILKALLSYHAWIFESHGKISFCTKLWLSLVKMLSGRRPLLYSFQTSLPRLPVPS HS CPT IA IVTMRYSLKVLLSYHGWMFTEHGKMSRATKIWMGMVKIF SGRKPMLYSFQTSLPRLPVPA HS CPT IB IFFFRQTLKLLLCYHGWMFEMHGKTSNLTRIWAMCIRLLSSRHPMLYSFQTSLPKLPVPR

Sa CPT I VDDTIORYLESVRPLLDTKOYNOMEILANDFKESKAAQLQRYLILKSWWATNYVSDWWEE Om CPT I VDDTITRYLESVRPLLDDEOYNQMEVVANDFKKDOAPKLOKYLILKSWWATNYVSDWWEE HS CPT IA VKDTVNRYLQSVRPLMKEEDFKRMTALAQDFAVGLGPRLQWYLKLKSWWATNYVSDWWEE HS CPT IB VSATIQRYLESVRPLLDDEEYYRMELLAKEFQDKTAPRLQKYLVLKSWWASNYVSDWWEE

Sa CPT I YIYLRSRSPIMVNSNFYIMDLLYMTPTHRQAARAGNVVHAMLOYRRKLERGEHAPLRALG Om CPT I YFYLRGRSP IMVNSNFYSMDLLYVTPTHROAARAGNVVHAMLQYRRKLERGEHAPLRALG HS CPT IA YIYLRGRGPLMVNSNYYAMDLLYILPTHIQAARAGNAIHAILLYRRKLDREEIKPIRLLG Hs CPT IB YIYLRGRSPLMVNSNYYVMDLVLIKNTDVQAARLGNI IHAMIMYRRKLDREEIKPVMALG

Sa CPT I . TVPMCSTOMERMFNTTRIPGIETDVVOHLTDRKHLLVYHKGRFFOVWLYTGGRHLLPGE Om CPT I .VVPMCSYOMERMFNTTRIPGIETDFVOHLSDRKHLVVYHKGCFFKVWLYYGGRHLWPSE HS CPT IA STIPLCSAOWERMFNTSRIPGEETDTIOHMRDSKHIVVYHRGRYFKVWLYHDGRLLKPRE HS CPT IB . IVPMCSYQMERMFNTTRIPGKDTDVLQHLSDSRHVAVYHKGRFFKLWLYEGARLLKPQD

Sa CPT I LETQFORILNDTSEPQPGELKLAALTAGSRVPWARARIKYFGQGVNKASLDAIESAAFFI Om CPT I LETQFQRILDDTTKPQPGELKLAAHTAGKRVPWARARLKYFSQGVNKASLEAIETSAFFL HS CPT IA MEQQMQRILDNTSEPQPGEARLAALTAGDRVPWARCRQAYFGRGKNKQSLDAVEKAAFFV HS CPT IB LEMQFQRILDDPSPPQPGEEKLAALTAGGRVEWAQARQAFFSSGKNKAALEAIERAAFFV

Sa CPT I TLDDEPQGYDP. AKTRSLDSYAKSLLHGKCYDRWFDKSFNLISYPNGKMGINAEHSWADA Om CPT I SLDDEAHGYDP. DKLRSLDLYAKSLLHGKCYDRWFDKSFTLIAYKNGKLGVNAEHSWADA HS CPT IA TLDETEEGYRSEDPDTSMDSYAKSLLHGRCYDRWFDKSFTFVVFKNGKMGLNAEHSWADA HS CPT IB ALDEESYSYDPED. EASLSLYGKALLHGNCYNRWFDKSFTLISFKNGQLGLNAEHAWADA

Sa CPT I PIVGHMWEYVLATDCFHLGYTEEGHCKGDVNKGLPCPSRLQWQIPAECQEAIEKSYLSGK Om CPT I PIIGHMWEYVLATDCFLLGYTEEGHCKGDINKGLPLPTKLQWDIPLECQEVIEESYMVAK HS CPT IA QIVAHLWEYVMSIDSLQLGYAEDGHCKGDINPNIPYPTRLQWDIPGECQEVIETSLNTAN HS CPT IB PIIGHLWEFVLGTDSFHLGYTETGHCLGKPNPALAPPTRLQWDIPKQCQAVIESSYQVAK

Sa CPT I QIADDVDFHGCLFTEFGKGLIKKCRTSPDAFIQLALQLAQFRDQGVFCLTYESSMTRMFR Om CPT I VIADDVDFHGCLFDEFGKGLIKKSRTSPDAFIQLALQLAQFRDKGEFCLTYEASMTRMFR Hs CPT IA LLANDVDFHSFPFVAFGKGIIKKCRTSPDTFVQLALQLAHYKDMGKFCLTYEASMTRLFR Hs CPT IB ALADDVELYCFQFLPFGKGLIKKCRTSPDAFVQIALQLAHFRDRGKFCLTYEASMTRMFR

Sa CPT I DGRTETVRSCTSEAEAFVRAMEDAGATKAQRLALFRKAADKHQNMYRLAMTGSGIDRHLF Om CPT I EGRTETVRSCTSESTAFVRAMEDKNTASAQKLDLFRKAADKHQNMYRLAMTGSGIDRHLF Hs CPT IA EGRTETVRSCTTESCDFVRAMVDPAQTVEQRLKLFKLASEKHOHMYRLAMTGSGIDRHLF HS CPT IB EGRTETVRSCTSESTAFVQAMMEGSHTKADLRDLFQKAAKKHQNMYRLAMTGAGIDRHLF

Sa CPT I CLYIVSKYLGVDSPFLKKVLSEPWKLSTSQTPQQQLNLVDINKFPKYVGAGGGFGPVADD Om CPT I CLYIMSKYLSIHSPFLKOVLSEPWRLSTSQTPQQQLNMVDIKKFPRYVGAGGGFGPVADD HS CPT IA CLYVVSKYLAVESPFLKEVLSEPWRLSTSQTPQQQVELFDLENNPEYVSSGGGFGPVADD HS CPT IB CLYLVSKYLGVSSPFLAEVLSEPWRLSTSQIPQSOIRMFDPEQHPNHLGAGGGFGPVADD

Sa CPT I GYGVSYIIVGENLITFHISCKFSSPDTDSYRFGQHIWKAMVDIQALFKPENNKKIVEHAK Om CPT I GYGVSYIIIGENLITFHISSKFSSPETDSYRFGQNIRQAMLDIRALFDQKDKKEM HS CPT IA GYGVSYILVGENLINFHISSKFSCPETDSHRFGRHLKEAMTDIITLFGLSSNSKK HS CPT IB GYGVSYMIAGENTIFFHISSKFSSSETNAQRFGNHIRKALLDIADLFQVPKAYS

Fig. 1. Alignment of the deduced amino acid sequence for the sea bream (Sa) and trout (Om) CPT1 (GenBank :AF327058) with those of the human (Hs) liver (1A, GenBank:L39211) and muscle (1B, GenBank:NM_004377) CPT1 isoforms. Residues identical in at least three of the sequences are shaded. Numbering on the right of the sequence corresponds to the sea bream residues. 


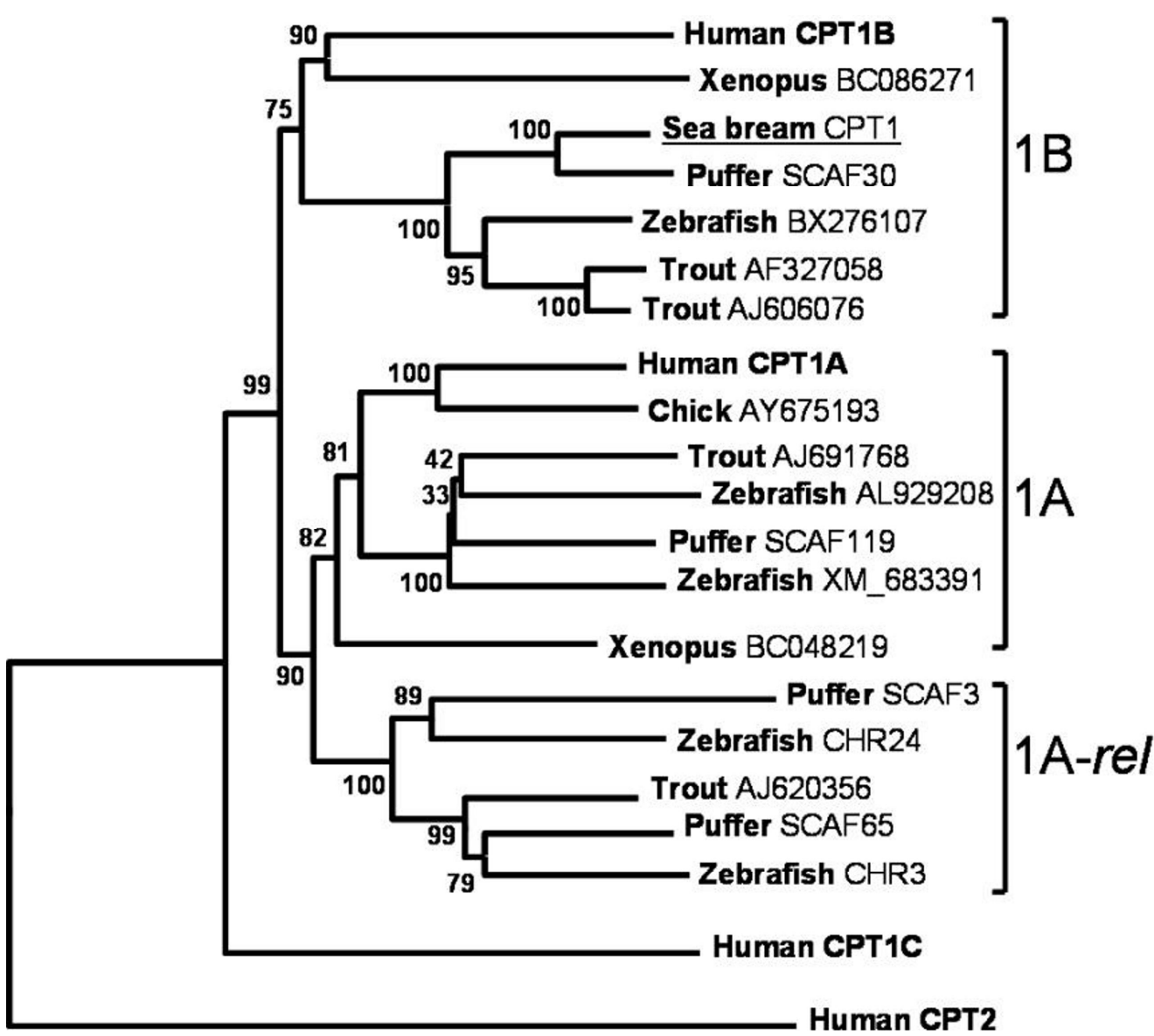

Fig. 2. Neighboring-joining tree (P-distance) for the protein sequence of CPT1 from sea bream and other vertebrate species. The tree was rooted to the human CPT2 (GenBank:NM_000098) protein sequence. Where available, GenBank accession numbers for the non-human sequences used to construct the tree are given following the species common name. Pufferfish (Puffer) sequences and some zebrafish sequences were derived by homology searches of the respective genomes (ENSEMBL Danio rerio Zv6; Takafugu rubripes FUGU4.0; www.ensembl.org/) against the sea bream CPT1 using TBLASTN. Proteins encoded by areas of genomic sequence with high homology to sea bream CPT1 were then derived using Wise2 (www.ebi.ac.uk/Wise2/). CHR or SCAF indicates the zebrafish chromosome number or pufferfish genomic scaffold for sequences derived this way. Distinct clades of the tree are shown to indicate the clustering of non-human sequences with either human CPT1A (GenBank:L39211), CPT1B (GenBank:NM_004377) or to show a fish-specific clade (1A-rel). Values at branch-points represent percentage frequencies for tree topology after 1000 iterations.

\subsection{Tissue mRNA expression of the sea bream CPT1.}

In order to examine the tissue mRNA expression of the sea bream CPT1 we initially performed the RNase protection assay on total RNA isolated from a variety of sea bream tissues.As shown in Figure 3A, the CPT1 transcripts are abundant in the red and white muscle tissues, as well as in the heart of sea bream. The CPT1 mRNA was also detected, albeit at lower level, in the fish brain. Weak CPT1 signals, at the limit of detection of the method, were observed in tissues such as kidney and liver, while no signal was detected in spleen, intestine, gills, and adipose tissue. Quantitative real-time (Q-PCR) confirmed the results of RNase protection, with the mRNA expression of CPT1 being high in skeletal and cardiac muscle and low or very low in all other tissues tested (Fig. 3B). Thus, in accordance with the phylogenetic 
analysis the tissue mRNA expression analysis suggests that the identified sea bream cDNA encodes for a muscle-specific CPT1 isoform (CPT1B).
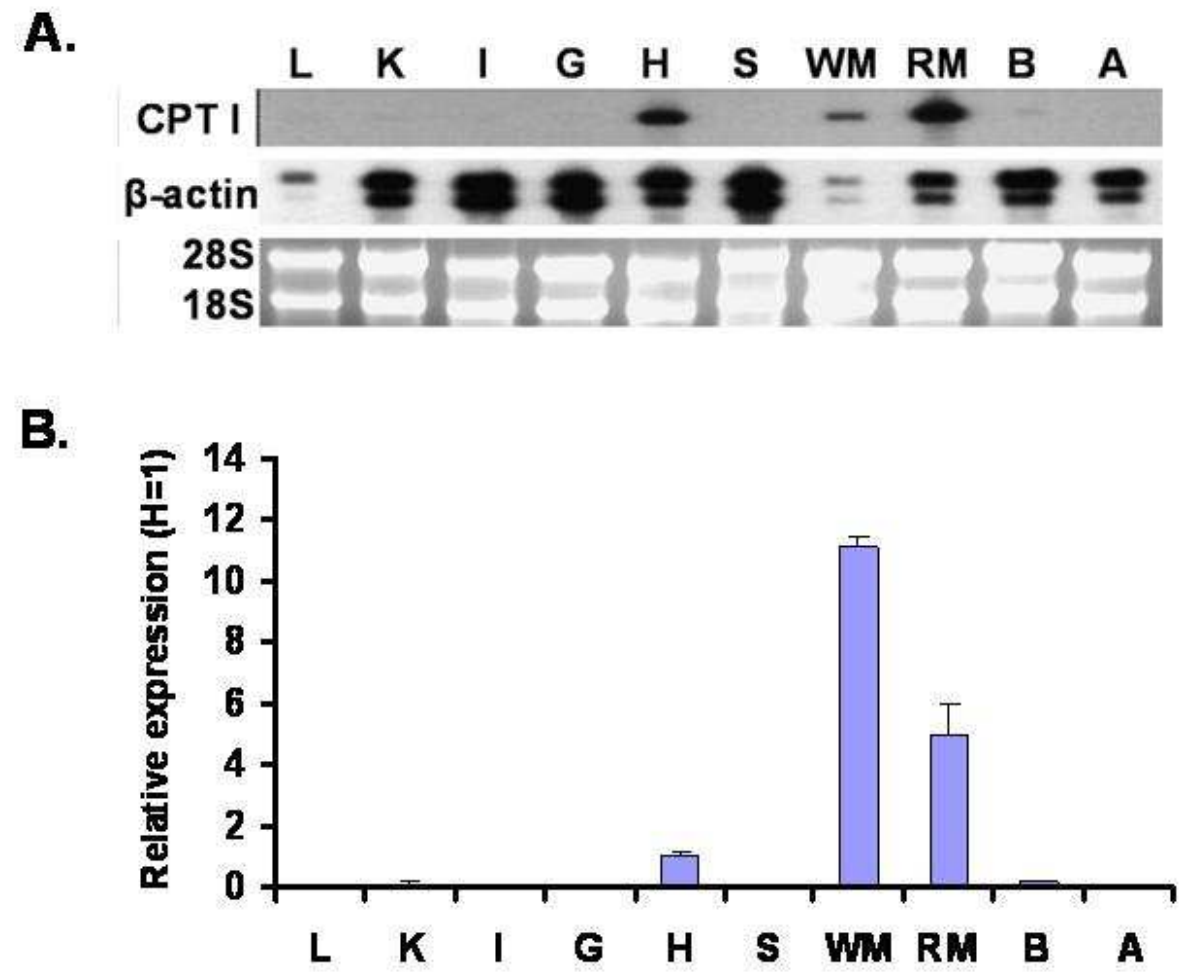

Figure 3. CPT1B mRNA expression in the tissues of sea bream. A. RNase protection analysis in the liver (L), kidney $(\mathrm{K})$, intestine (I), gills $(\mathrm{G})$, heart $(\mathrm{H})$, spleen $(\mathrm{S})$, white muscle $(\mathrm{W})$, red muscle $(\mathrm{R})$, brain $(\mathrm{B})$, and mesenteral adipose (A). Each lane contains the RNase-protected fragments from $8 \mu \mathrm{g}$ of total RNA from each tissue incubated with 3 fmoles of the radiolabeled CPT1B and $\beta$-actin riboprobes. A 1/8 fraction $(1 \mu \mathrm{g})$ of the input total RNA used in the RNase protection assay is also shown and the main ribosomal RNAs (28 and 18S) are indicated. B. Quantitative real time-PCR (Q-PCR) analysis for the expression of CPT1B. Tissues are as in panel A. Data represent the mean $( \pm \mathrm{SD})$ of independent experiments on tissues of at least three different fish. Values, normalized to the expression of the EF1a gene, are relative to the expression of CPT1B in the heart $(\mathrm{H})$ of sea bream, which was arbitrarily set as one $(\mathrm{H}=1)$.

\subsection{CPT1B mRNA expression is regulated by the feeding status.}

To examine the possibility that CPT1 expression is also feeding status-dependent and PPAR-mediated in sea bream, we monitored the mRNA expression of CPT1 and of the three PPAR isotypes in muscle, heart, and liver tissue samples obtained at different time points following the feeding of fish. CPT1 mRNA expression was high in red muscle at $1 \mathrm{~h}$ postfeeding and dropped significantly at 5 and 8 hrs post-feeding (Fig. 4). At $12 \mathrm{~h}$ post-feeding, CPT1 mRNA expression increased and reached initial levels at the $72 \mathrm{~h}$ time point. In this tissue, PPAR $\alpha$ mRNA expression was significantly increased at $5 \mathrm{~h}$ post-feeding but decreased at later time points (Fig. 4). Red muscle PPAR $\beta$ and PPAR $\gamma$ mRNA expression was not affected during the course of the experiment, with the exception of a significant increase in PPAR $\gamma$ transcript level at $72 \mathrm{~h}$ post-feeding (Fig. 4).

In white muscle, CPT1 mRNA expression decreased gradually during the first $12 \mathrm{~h}$ post-feeding. At later time points, the expression of this gene increased significantly exceeding the $1 \mathrm{~h}$ value at the $72 \mathrm{~h}$ time point (Fig. 4). In this tissue, PPAR $\alpha$ mRNA expression was extremely low as compared to that of the CPT1B and of the other two PPAR isotypes and 
exhibited a decreasing trend through the course of the experiment (Fig. 4). At $1 \mathrm{hr}$ post feeding PPAR $\beta$ was the most highly expressed gene, among the four studied, in the white muscle of sea bream. Similar to CPT1B, its expression decreased during the first $12 \mathrm{~h}$ post feeding but increased significantly at the 24 and $72 \mathrm{~h}$ time points (Fig. 4). White muscle PPAR $\gamma$ mRNA expression did not vary significantly during the course of the experiment, with the exception of elevated transcript levels observed at the $12 \mathrm{~h}$ time point (Fig. 4).

As was the case in red muscle, CPT1B mRNA in sea bream heart was also relatively highly expressed and exhibited a similar trend in response to short-term fasting, i.e. its expression was decreased during the first $12 \mathrm{~h}$ and then gradually increased to equal or higher values of the initial time point (Fig. 4). Heart PPAR $\alpha$ mRNA expression decreased significantly at 12 and $24 \mathrm{~h}$, as compared to its levels at 3,5, and $8 \mathrm{~h}$ following feeding (Fig. 4). No significant changes in PPAR $\beta$ expression were observed in the sea bream heart during the course of the experiment, while the expression of PPAR $\gamma$, albeit at relatively low levels, exhibited a significant increasing trend after the $8 \mathrm{~h}$ time point (Fig. 4). Finally, expression of CPT1B in the liver was very low during the first $12 \mathrm{~h}$ post-feeding but increased significantly at the 24 and $72 \mathrm{~h}$ time points (5 and 10 fold, respectively). PPAR $\gamma$ expression followed an opposite trend, with increased values during the first hours and decreased expression at later times (Fig. 4).

From the above it is evident that the expression CPT1B and of the three PPAR isotypes is significantly regulated at the gene level in the tissues of sea bream in response to feeding and fasting. Furthermore, our results demonstrate that there is a positive and highly significant correlation between the expression of CPT1B and PPAR $\beta$ in the white muscle $(0.937, p<$ $0.005)$ and liver $(0.912, p<0.005)$ of sea bream. In contrast, the expression pattern of either PPAR $\alpha$ or PPAR $\gamma$ does not appear to follow the trend of CPT1B in any of the tissues tested (correlation coefficient $<0.7, \mathrm{p}>0.05$, Supplementary Table 1).

\section{DISCUSSION}

In this report, we have identified and chracterized a cDNA from the muscle tissue of sea bream that encodes a protein with significant similarity to CPT1 proteins from mammalian and fish species. In contrast to the trout protein, where a 21 residue deletion has been observed at its amino-terminal region (Gutières et al., 2003), the sea bream protein aligns perfectly with the mammalian sequences in the corresponding region. Thus, the residues of the amino-terminal region established to be important for malonyl-CoA sensitivity in the liver (CPT1A) and muscle (CPT1B) isoforms of mammalian CPT1 (Shi et al., 1999, Shi et al., 2000) are conserved in the sea bream protein. Furthermore, the N-terminal domain (residues 1-150) of mammalian CPT1 has been implicated in the insertion of the protein in the outer mitochondrial membrane (Cohen et al., 1998). The high identity between the sea bream and mammalian sequences in this region suggests that the elements responsible for membrane insertion are also conserved in the sea bream CPT1. In support of this, Von Heijne hydrophobicity analysis (Von Heijne, 1992) predicts the presence of two transmembrane helices spanning residues 50-80 and 100-136 in the sea bream sequence in good agreement with the predicted location of the transmembrane helices in the trout protein (Gutières et al., 2003). 
A
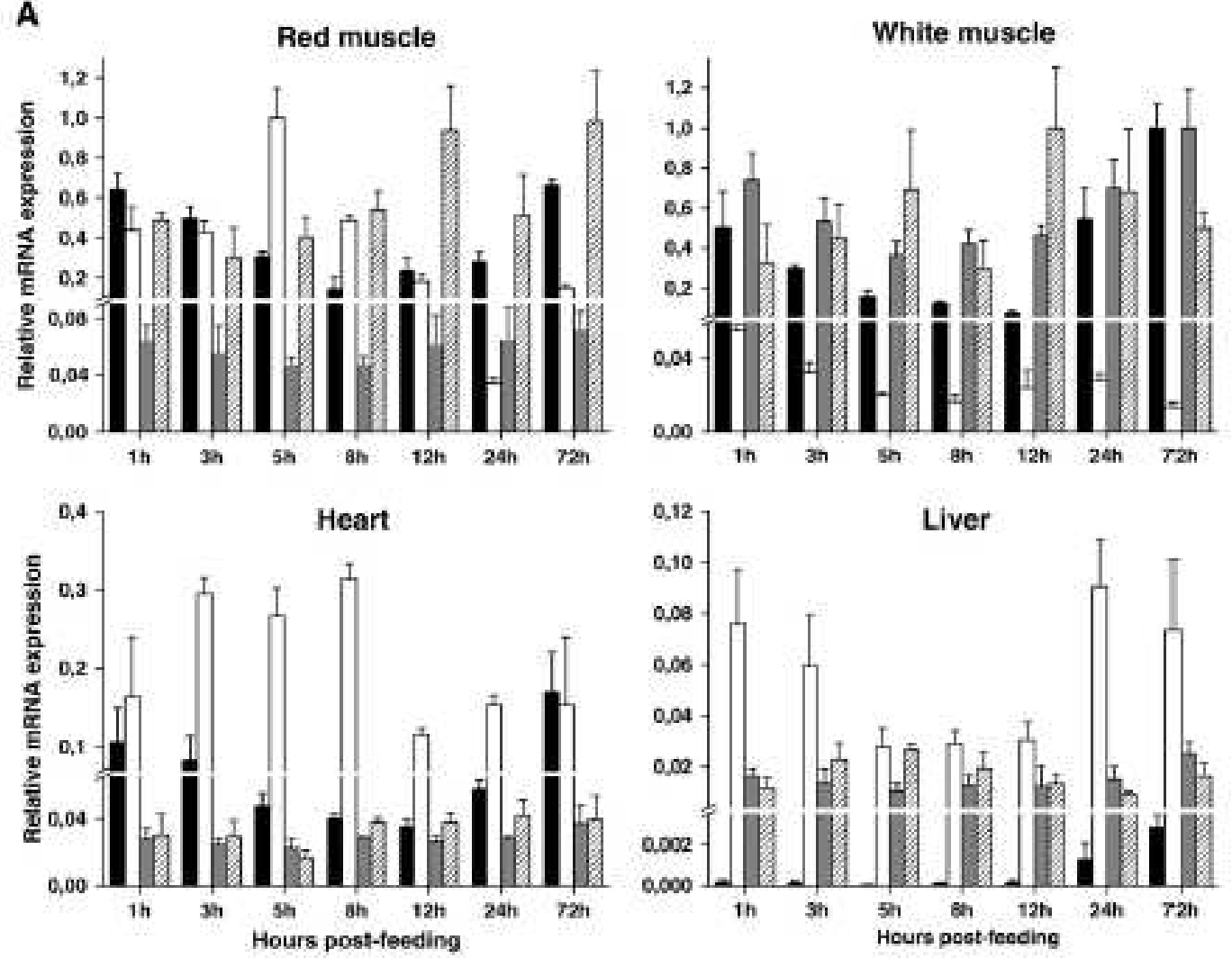

B

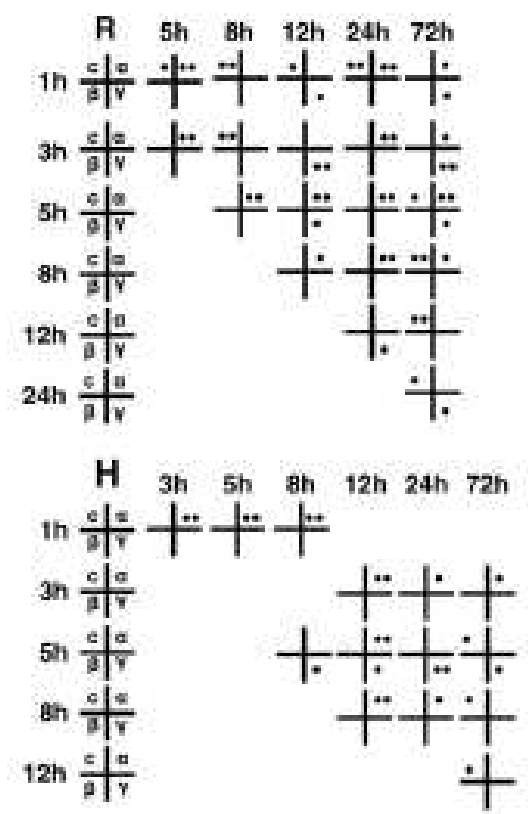

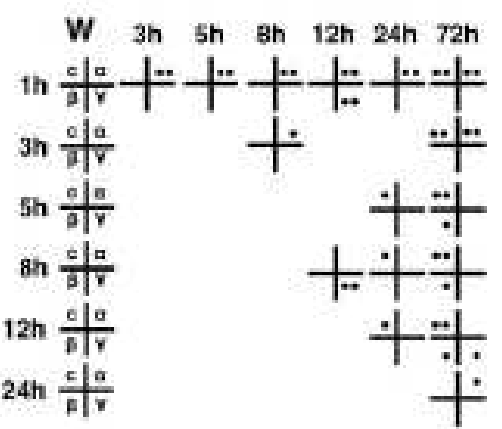

L. $5 \mathrm{~h}$ Bh $12 \mathrm{~h} 24 \mathrm{~h} 72 \mathrm{~h}$

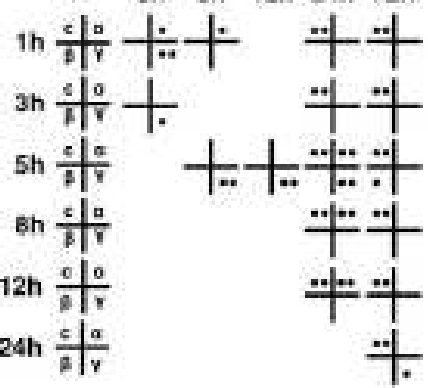

Fig. 4. Post-prandial mRNA expression of CPT1B and PPAR isotypes in tissues of sea bream. Expression of CPT1B and of the three PPAR isotypes in the sea bream red muscle $(\mathrm{R})$, white muscle $(\mathrm{WM})$, heart $(\mathrm{H})$, and liver $(\mathrm{L})$ at different time points following feeding was assessed by Q-PCR. Values are normalized to the expression of the EF1a gene and represent the mean $( \pm \mathrm{SD})$ of independent experiments on tissues of five different fish. Significant differences $(p<0.05)$ between time points are indicated by letters, where $\mathbf{a}, \mathbf{b}, \mathbf{c}, \mathbf{d}, \mathbf{e}$, and $\mathbf{f}$ correspond to the $1,3,5,8$, 12 , and 24 hrs time points, respectively. 
Of the functional motifs identified in the sea bream protein, both of the predicted carnitine acyltransferase sites (within residues 171-186 and 449-476, see also Fig. 1) are also found in corresponding positions in the mammalian liver and muscle isoforms. In contrast, from the two potential asparagine glycosylation sites at residues 312 and 367, only the first is conserved in the protein from other species. Interestingly, the potential tyrosine phosphorylation site at residue 191 is conserved only in the mammalian CPT1B. This site is also present in the originally reported trout protein (Gutières et al., 2003). Importantly, all of the above residues are located on the part of the protein exposed to the cytosol, according to the topology suggested for the mammalian CPT1 (Fraser et al., 1997).

In mammalian CPT1, extensive mutagenesis studies have identified a number of residues in the C-terminal domain of the protein that are important for malonyl-CoA sensitivity and catalytic activity. Thus, in the rat liver enzyme, residues Glu-590, Arg-601, Glu-603, and Arg-606 are involved both in catalysis and malonyl-CoA sensitivity as mutations on these sites affect both properties (Treber et al., 2003, Napal et al., 2003). The above residues are conserved in the sea bream CPT1 (Glu-588, Arg-599, Glu-601, and Arg-604, respectively in Fig. 1), suggesting a common function in the properties of the protein. Furthermore, the residues proposed to form the catalytic triad of the mammalian muscle CPT1 isoform (CPT1B), i.e. Cys305, Asp-454, His-473 (Liu et al., 2005), are also conserved in the sea bream enzyme (Cys-303, Asp-453, His 471, respectively in Fig. 1).

Very few previous reports have addressed CPT1 genes in fish species, despite their potential importance in determining utilisation of lipid in aquaculture diets. In an early study of a trout CPT1 cDNA it was suggested that a single CPT1 gene is present in trout, due to the ubiquitous presence of its transcripts in the tissues of the fish (Gutières et al., 2003). However, more recent evidence, including the catalytic examination of CPT1 activity in trout tissues, has indicated the presence of multiple CPT1 proteins (Morash et al., 2008). The sequence data available now supports the presence of multiple CPT1 genes in trout and several other studies have reported the measurement of various trout CPT1 mRNAs (Kolditz et al., 2008; Lansard et al., 2009; Morash et al., 2009; Plagnes-Juan et al., 2008; Polakof et al., 2010). The inclusion in the phylogenetic analysis performed in the present work of all know trout sequences, along with CPT1-like sequences from pufferfish and zebrafish, suggests that the sea bream protein is more closely related to the mammalian muscle CPT1 isoform, CPT1B. Furthermore, it reveals the potential complexity of the CPT1 system in fish, which it may be even more accentuated in species such as trout with a recently duplicated genome (Allendorf and Thorgaard, 1984). Thus we show that fish species possess multiple CPT1 genes, including a homlogue of mammalian CPT1B and up to four genes similar to mammalian CPT1A. Moreover, we show that two of the four known rainbow trout genes (GenBank: AF327058 and AJ606076, termed CPT1A and CPT1B, respectively in Kolditz et al., 2008) are likely to be duplicated CPT1B genes. In zebrafish at least two distinct genes appear to encode each for a CPT1A-like isoform. In addition, zebrafish, pufferfish, and trout harbour in their genomes genes encoding a family of CPT1 proteins (CPT1A-rel in Fig. 2) that are distinct from the three known mammalian CPT1 isoforms. The complexity of the system increases drastically if one considers the possibility of different splice variants of the above mRNAs and their corresponding proteins with potentially distinct functional roles and/or cellular targeting as has been previously suggested (Yu et al., 1998b; Van der Leij et al., 2002).

In accordance with the phylogenetic analysis, the tissue mRNA expression results indicate that the identified sea bream CPT1 is predominantly expressed in the muscle and heart tissues of sea bream with little or no expression in the other tissues tested. These results are very similar to those reported for the mRNA expression of a trout CPT1 (Morash et al., 2008). 
Therefore, we conclude that the identified cDNA encodes for a muscle-specific isoform of CPT1 and is therefore orthologous to the mammalian CPT1B.

We have also demonstrated that the expression of the sea bream CPT1B isoform is regulated at the gene level according to feeding status. In general, our observations suggest that feeding results in a rapid post-prandial decrease in expression of CPT1B in white and red muscle and heart, followed by a return to pre-prandial levels at or after $24 \mathrm{~h}$ post-feeding. This pattern of expression/activity of CPT1B mRNA is likely to reflect the enzyme concentration required by the tissue to meet its energy needs. Thus, synthesis of new enzyme/increased activity 24 hours after last feeding appears to be required when the substrates, i.e. fatty acylCoAs, are not available from dietary sources but are derived from the mobilization of the fat reserves of the fish. This mobilization is related to the large increase of CPT1B mRNA in liver after $24 \mathrm{~h}$, reflecting the role of this tissue in co-ordinating the response to fasting. Measurement of a trout CPT1B-like mRNA (GenBank: AF606076) showed a decrease in hepatic expression following refeeding after 5 days fasting (Lansard et al, 2010), and this CPT1B-like and another closely related trout CPT1B- like mRNA (GenBank: AF327058) were both reduced after insulin treatment of fish which were not fed for 48 hours previously (Plagnes-Juan, et al., 2008). These effects are generally in agreement with our results for sea bream, and indicate that fish hepatic CPT1B is increased as food supply is reduced, and decreased post-prandially. These dwonregulating effects may be mediated by rises in insulin caused by feeding. Down-regulation of CPT1B-like mRNA in trout muscle after chronic or acute insulin treatment has also been recently demonstrated (Polakof et al., 2010).

Although insulin is a clear candidate for mediating reduced CPT1B expression, PPARs have been shown to up-regulate CPT1 gene expression in mammals (Baldán et al., 2004, Gilde et al., 2003, Mescaró et al., 1998). The parallel examination of the expression of the three PPAR isotypes in this post-prandial experiment revealed a positive and strong correlation between the expression pattern of CPT1B and that of PPAR $\beta$ in the white muscle and also the liver of sea bream. Thus, in liver the mRNA expression of PPAR $\square$ was as previously reported (Leaver et al., 2005; Diaz et al., 2007), i.e. its expression decreased during the first $5 \mathrm{hrs}$ post feeding, then gradually increased to reach or surpass the initial values at the 24 and $72 \mathrm{~h}$ time points. The same pattern was also observed for PPAR $\beta$ in the sea bream white muscle, following closely the expression of CPT1B. In contrast, the expression pattern of CPT1B was not related to that of either PPAR $\alpha$ or PPAR $\gamma$ in any of the sea bream tissues tested. These results suggest that PPAR $\beta$, but not PPAR $\alpha$ or PPAR $\gamma$, is involved in the regulation of expression of CPT1B in sea bream tissues in response to feeding and fasting. Relevant to this, PPAR $\beta$ has been shown to up-regulate lipid oxidation in the muscle of fasting mammals, a process that also involves the increased expression of CPT1B (de Lange et al., 2008).

To our knowledge, this is the first report that examines the post-prandial CPT1 mRNA expression in a fish species in a timedependent manner and it complements our previous observations on the post-prandial expression of the three PPAR isotypes in sea bream (Leaver et al., 2005; Diez et al., 2007). Most studies on the mRNA expression and/or activity of CPT1 isoforms in fish concern the response to either dietary or hormonal treatments (Kolditz et al., 2008; Lansard et al., 2009; Leaver et al., 2006; Morash et al., 2009; Plagnes-Juan et al., 2008; Polakof et al., 2010). In the few studies where the expression of PPAR isotypeswas studied in parallel to that of CPT1, no clear association between the expression of the CPT1 and PPAR genes was observed (Kolditz et al., 2008; Leaver et al., 2006; Morash et al., 2009).

Clearly, mRNA expression data alone are not sufficient to indicate changes in CPT1 catalytic activity or to exclude the involvement of PPAR $\alpha$ and/or PPAR $\gamma$ in the regulation of this gene in the tissues of sea bream. Enhancement or repression of PPAR isotype expression is 
not a necessary prerequisite for corresponding induction/repression of their target genes. The transcriptional activity of these receptors is also subject to the tissue-specific availability of coactivators or corepressors and on phosphorylation state (Desvergne and Wahli, 1999, Xu et al., 1999). Definite conclusions concerning the involvement of particular, if any, PPAR isotypes in the transcriptional regulation and activity of CPT1 in sea bream, or other fish speciesmust await the characterization of other identified CPT1 genes, the promoter structures of thesegenes and the catalytic activities of their products

\section{ACKNOWLEDGMENTS}

This work was supported in part by the European Commission (Project Number Q5RS2000-30360). E.B. was supported in part by an OECD fellowship. The sequence described herein has been deposited to the EMBL/GenBank databases under accession no. DQ866821.

\section{Appendix A. Supplementary data}

Supplementary data associated with this article can be found, in the online version, at doi:10.1016/j.cbpb.2010.06.004. .

\section{REFERENCES}

Allendorf, F.W., Thorgaard, G., 1984. Tetraploidy and the evolution of salmonid fishes. In: Turner, B.J. (Ed.), The Evolutionary Genetics of Fishes. Plenum Press, New York, pp. $1-53$.

Baldán, A., Relat, J., Marrero, P.F., Haro, D., 2004, Functional interaction between peroxisome proliferator-activated receptors- $\alpha$ and Mef- $2 \mathrm{C}$ on human carnitine palmitoyltransferase $1 \beta$ (CPT1 $\beta$ ) gene activation. Nucleic Acids Res. 32, 4742-4749.

Boukouvala, E., Antonopoulou, E., Favre-Krey, L., Diez, A., Bautista, J.M., Leaver, M.J., Tocher, D.R., Krey, G., 2004, Molecular characterization of three peroxisome proliferators-activated receptors from the sea bass (Dicentrarchus labrax). Lipids 39, 1085-1092.

Brandt, J.M., Djouadi, F., Kelly, D.P., 1998, Fatty acids activate transcription of the muscle carnitine palmitoyltransferase I gene in cardiac myocytes via the peroxisome proliferators-activated receptor $\alpha$. J. Biol. Chem. 273, 23786-23792.

Britton, C.H., Schultz, R.A., Zhang, B., Esser, V., Foster, D.W., McGarry, J.D., 1995, Human liver mitochondrial carnitine palmitoyltransferase I: Characterization of its cDNA and chromosomal localization and partial analysis of the gene. Proc. Natl. Acad. Sci. U.S.A. 92, 1984-1988.

Cohen, I., Kohl, C., McGarry, J.D., Girard, J., Prip-Buus, C., 1998, The N-terminal domain of rat liver carnitine palmitoyltransferase 1 mediates import into the outer mitochondrial membrane and is essential for activity and malonyl-CoA sensitivity. J. Biol. Chem. 273, 29896-29904.

Cook, G.A., Edwards, T.L., Jansen, M.S., Bahouth, S.W., Wilcox, H.G., Park, E.A., 2001, Differential regulation of carnitine Palmitoyltransferase-1 gene Isoforms (CPT-1a and CPT-1b) in the Rat Heart. J. Mol. Cell. Cardiol. 33, 317-329.

De Lange, P., Lombardi, A., Silvestri, E., Goglia, F., Lanni, A., Moreno, M., 2008, Peroxisome Proliferator-Activated Receptor Delta: A Conserved Director of Lipid Homeostasis through Regulation of the Oxidative Capacity of Muscle. PPAR Res. Article ID 172676. 
Desvergne, B., Ijpenberg, A., Devchand, P.R., Wahli, W., 1998, The peroxisome proliferatoractivated receptors at the cross-road of diet and hormonal signalling. J. Ster. Biochem. Mol. Biol. 65, 65-74.

Desvergne, B., Wahli, W., 1999, Peroxisome proliferator-activated receptors: nuclear control of metabolism. Endocr. Rev. 20, 649-688.

Diez, A., Menoyo, D., Pérez-Benavente, S., Calduch-Giner, J.A., Vega-Rubin de Celis, S., Obach, A., Favre-Krey, L., Boukouvala, E., Leaver, M.J., Tocher, D.R., Pérez-Sanchez, J., Krey, G., Bautista, J.M., 2007. Conjugated linoleic acid affects lipid composition, metabolism, and gene expression in gilthead sea bream (Sparus aurata L). J. Nutr. 137, 1363-1369.

Esser, V., Brown, N.F., Cowan, A.T., Foster, D.W., McGarry, J.D., 1996, Expression of a cDNA isolated from rat brown adipose tissue and heart identifies the product as the muscle isoform of carnitine palmitoyltransferase I (M-CPT I). J. Biol. Chem. 271, 6972-6977.

Fraser, F., Corstorphine, C.G., Zammit, V.A., 1997, Topology of carnitine palmitoyltransferase $\mathrm{I}$ in the mitochomdrial outer membrane. Biochem. J. 323, 711-718.

Gao, X.F., Chen, W., Kong, X.P., Xu, A.M., Wang, Z.G., Sweeney, G., Wu, D., 2009, Enhanced susceptibility of Cpt1c knockout mice to glucose intolerance induced by a high-fat diet involves elevated hepatic gluconeogenesis and decreased skeletal muscle glucose uptake. Diabetologia 52, 912-920.

Gilde, A.J., van der Lee, K.A.J.M., Willemsen, P.H.M., Chinetti, G., van der Leij, F.R., van der Vusse, G.J., Staels, B., van Bilsen, M., 2003, Peroxisome proliferators-activated receptor (PPAR) $\alpha$ and PPAR $\beta / \delta$ but not PPAR $\gamma$, modulate the expression of genes involved in cardiac lipid metabolism. Circ. Res. 92, 518-524.

Gutières, S., Damon, M., Panserat, S., Kaushik, S., Médale, F., 2003, Cloning and tissue distribution of a carnitine palmitoyltransferase I gene in rainbow trout (Oncorhynchus mykiss). Comp. Biochem. Physiol. B 135, 139-151.

Kersten, S., Seydoux, J., Peters, J.M., Gonzales, F.J., Desvergne, B., Wahli, W., 1999, Peroxisome proliferator-activated receptor $\alpha$ mediates the adaptive response to fasting. J. Clin. Invest. 103, 1489-1498.

Kolditz, C., Borthaire, M., Richard, N., Corraze, G., Panserat, S., Vachot, C., Lefevre, F., Medale, F., 2008. Liver and muscle metabolic changes induced by dietary energy content and genetic selection in rainbow trout (Oncorhynchus mykiss). Am. J. Physiol. Regul. Integr. Comp. Physiol. 294, 1154-1164.

Kumar, S., Tamura, K., Jakobsen, I.B., Nei, M., 2001, MEGA2: molecular evolutionary genetics analysis software. Bioinformatics 17, 1244-1245.

Lansard, M., Panserat, S., Seiliez, I., Polakof, S., Plagnes-Juan, E., Geurden, I., Médale, F., Kaushik, S., Corraze, G., Skiba-Cassy, S., 2009. Hepatic protein kinase B (Akt)-target of rapamycin (TOR)-signalling pathways and intermediary metabolism in rainbow trout (Oncorhynchus mykiss) are not significantly affected by feeding plant-based diets. Br. J. Nutr. 102, 1564-1573.

Leaver, M.J., Boukouvala, E., Antonopoulou, E., Diez, A., Favre-Krey, L., Ezaz, M.T., Bautista, J.M., Tocher, D.R., Krey, G., 2005, Three peroxisome proliferators-activated receptor isotypes from each of two species of marine fish. Endocrinology 146, 31503162.

Leaver, M.J., Bautista, J.M., Björnsson, B.T., Jönsson, E., Krey, G., Tocher, D.R., Torstensen, B.E., 2008, Towards Fish Lipid Nutrigenomics: Current State and Prospects for FinFish Aquaculture. Rev. Fish. Sci. 161, 71-92. 
Leone, T., Weinheimer, C.J., Kelly, D.P., 1999, A critical role for the peroxisome proliferatorsactivated receptor $\alpha$ (PPAR $\alpha)$ in the cellular fasting response: The PPAR $\alpha$-null mouse as a model of fatty acid oxidation disorders. Proc. Natl. Acad. Sci. U.S.A. 96, 74737478.

Liu, H.Y., Zheng, G., Treber, M., Dai, J., Woldergiorgis, G., 2005, Cysteine-scanning mutagenesis of muscle carnitine palmitoyltransferase I reveals a single cysteine residue (Cys-305) is important for catalysis. J. Biol Chem. 280, 4524-4531.

McGarry, J.D., Brown, N.F., 1997, The mitochondrial carnitine palmitoyltransferase system. From concept to molecular analysis. Eur. J. Biochem. 244, 1-14.

Mescaró, C., Acosta, E., Ortiz, J.A., Marrero, P.F., Hegardt, F.G., Haro, D., 1998, Control of human muscle-type carnitine palmitoyltransferase I gene transcription by peroxisome proliferator-activated receptor. J. Biol. Chem. 273, 8560-8563.

Morash A.J., Kajimura M, McClelland G.B., 2008, Intertissue regulation of carnitine palmitoyltransferase I (CPTI): Mitochondrial membrane properties and gene expression in in rainbow trout (Oncorhynchus mykiss), Biochem. Biophys. Acta 1778, 1382-1389.

Morash A.J., Kajimura M, McClelland G.B., 2009, Effect of dietary fatty acid composition on the regulation of carnitine palmitoyltransferase (CPT) I in rainbow trout (Oncorhynchus mykiss). Comp. Biochem. Physiol. B 152, 85-93.

Napal, L., Dai, J., Treber, M., Haro, D., Marrero, P.F., Woldegiorgis, G., 2003, A single amino acid change (substitution of the conserved Glu-590 with alanine) in the C-terminal domain of rat liver carnitine palmitoytransferase I increases its malonyl-CoA sensitivity close to that observed with the muscle isoform of the enzyme. J. Biol. Chem. 278, 34084-34089.

Pfaffl, M.W., 2001, A new mathematical model for relative quantification in real-time RTPCR. Nucl. Acids Res. 29, e45

Plagnes-Juan, E., Lansard, M., Seiliez, I., Medale, F., Corraze, G., Kaushik, S., Panserat, S., Skiba-Cassy, S., 2008. Insulin regulates the expression of several metabolismrelated genes in the liver and primary hepatocytes of rainbow trout (Oncorhynchus mykiss). J. Exp. Biol. 211, 2510-2518

Polakof, S., Médale, F., Skiba-Cassy, S., Corraze, G., Panserat, S., 2010. Molecular regulation of lipid metabolism in liver and muscle of rainbow trout subjected to acute and chronic insulin treatments. Domest. Anim. Endocrinol. 39, 26-33.

Price, N.T., van der Leij, F.R., Jackson, V.N., Corstophine, C.G., Thomson, R., Sorensen, A., Zammit, V.A., 2002, A novel brain -expressed protein related to carnitine palmitoyltransferase I. Genomics 80, 434-442.

Shi, J., Zhu, H., Arvidson, D.N., Woldegiorgis, G., 1999, A single amino acid change (substitution of glutamate 3 with alanine) in the N-terminal region of rat liver carnitine palmitoyltransferase I abolishes malonyl-CoA inhibition and high affinity binding. J. Biol. Chem. 274, 9421-9426.

Shi, J., Zhu, H., Arvidson, D.N., Woldegiorgis, G., 2000, The first 28 N-terminal amino acid residues of human heart muscle carnitine palmitoyltransferase I are essential for malonyl CoA sensitivity and high-affinity binding. Biochem. 39, 712-717.

Swofford, D.L., 2000, Phylogenetic analysis using parsimony (and other methods), Version 4b. Sinauer Asoociates, Sunderland, Massachusetts.

Treber, M., Dai, J., Woldegiorgis, G., 2003, Identification by mutagenesis of conserved arginine and glutamate residues in the $\mathrm{C}$-terminal domain of rat liver carnitine palmitoyltransferase I that are important for catalytic activity and malonyl-CoA sensitivity. J. Biol. Chem. 278, 11145-11149. 
van der Leij, F.R., Cox, K.B., Jackson, V.N., Huijkman, N.C.A., Bartelds, B., Kuipers, J.R.G., Dijkhuizen, T., Terpstra, P., Wood, P.A., Zammit, V.A., Price, N.T., 2002, Structural and functional genomics of the CPT1B gene for muscle-type carnitine palmitoyltransferase I in mammals. J. Biol. Chem. 277, 26994-27005.

Von Heijne, G., 1992, Membrane protein structure prediction. Hydrophobicity analysis and the positive-inside rule. J. Mol. Biol. 225, 487-494.

Xu, L., Glass, C.K., Rosenfeld, M.G., 1999, Coactivator and corepressor complxes in nuclear receptor function. Curr. Opin, Genet. Dev. 9, 140-147.

Yu, G.S., Lu, Y.C., Gulick, T., 1998, Co-regulation of tissue-specific alternative human carnitine palmitoyltransferase I $\beta$ gene promoters by fatty acid enzyme substrate. J. Biol. Chem. 273, 32901-32909.

Yu, G.S., Lu, Y.C., Gulick, T., 1998, Expression of novel isoforms of carnitine palmitoyltransferase I (CPT-1) generated by alternative splicing of the CPT-1 beta gene. Biochem. J. 334, 225-31. 